\title{
E como anda o ensino de literatura brasileira? Um estudo de práticas nos níveis fundamental e médio
}

Livia Suassuna ${ }^{\star}$

failton Nóbrega ${ }^{\star \star}$

\section{Resumo}

Considerando o contexto atual de ampliação da concepção de linguagem e de literatura, pretendeu-se descrever e analisar práticas de ensino de literatura brasileira nos níveis fundamental e médio, verificando se os conteúdos e as metodologias privilegiados pelos professores nas aulas de literatura são compatíveis com as mais recentes propostas para o ensino da disciplina. Entre outros, lançou-se mão dos trabalhos de Bordini e Aguiar (1993), Chiappini (2006) e Cosson (2006). Quanto à metodologia, realizou-se uma pesquisa qualitativo-etnográfica por meio da observação de aulas de literatura brasileira em duas escolas de perfis diferentes: uma pública municipal do Recife (ensino fundamental) e uma pública estadual de Pernambuco (ensino médio). Pôde-se notar práticas que não promovem o letramento literário. Enquanto um professor reduz suas aulas ao estudo de história da literatura, o outro não considera os aspectos estéticos desse gênero, nem leva em conta as interpretações e impressões dos educandos.

Palavras-chave: Ensino de literatura. Letramento literário. Prática pedagógica.

\section{Contextualizando e problematizando o ensino de literatura no Brasil}

Num texto sobre a história do ensino da língua portuguesa, Soares (1998) mostra que os estudos da linguagem na escola do Brasil Colônia eram apoiados em três bases - gramática, retórica e poética -, constituindo-se essa última em abordagens dos textos literários, analisados, frequentemente, na ótica da filologia clássica . Isto é, o texto literário era visto como exemplar da boa linguagem e dele se extraíam fragmentos para o estudo de aspectos gramaticais.

\footnotetext{
Docente Associada IV do Programa de Pós-Graduação de Letras Vernáculas da UFRJ; Docente Adjunta III do Programa de Pós-Graduação de Letras Vernáculas da UFRJ.

** Graduando em Letras-Português pela UFPE; bolsista do programa PIBIC-UFPE-CNPq - exercício 2011-2012; e-mail: jailtonobrega100@hotmail.com.
}

Data de submissão: fev. 2013 - Data de aceite: abr. 2013 http://dx.doi.org/10.5335/rdes.v9i1.3533 
Estudando a situação da literatura na legislação das reformas de ensino do século XX no Brasil, Lima (1996) constatou a falta de políticas específicas para o ensino desse componente curricular. $\mathrm{O}$ autor considera que a falta de política já é, em si, uma política e também traduz a pouca importância que se tem conferido ao estudo da literatura na escola, apesar de os estudos literários terem presença no ensino desde a época dos jesuítas no Brasil Colônia, como já apontado.

A Lei n. 5.692/71, que regeu a educação nacional durante o período da ditadura militar, estabeleceu uma nova terminologia para a língua portuguesa: a disciplina passou a chamar-se "comunicação e expressão", ficando a literatura brasileira restrita ao antigo $2^{\circ}$ grau. Nesse segmento, historicamente, a literatura sempre teve lugar secundário, com poucas aulas semanais, e funciona, até hoje, como uma disciplina autônoma, ao lado da gramática e da redação. No ensino fundamental, o texto literário figura, ainda hoje, como fonte do estudo gramatical e como objeto de interpretação. Esse panorama perdurou desde a época do Brasil Colonial até, pelo menos, a década de 1970.

Em meados dos anos 1980, o ensino de língua portuguesa começou a sofrer grandes transformações e questionamentos, devidos, principalmente, ao avanço dos estudos linguísticos, que passaram a ver a linguagem, para além de mera forma ou estrutura, como interação, prática social e discursiva. É marco desse momento histórico a publicação, em 1984, do livro $O$ texto na sala de aula - leitura e produção, organizado por João Wanderley Geraldi, o qual já continha alguns questionamentos sobre a concepção e o ensino da literatura. ${ }^{1}$

Nessa obra, Chiappini já indagava se a separação entre literatura e gramática faria algum sentido. Segundo a autora, estudar literatura seria estudar linguagem. Ela também apresenta cinco formas possíveis de se entender o conceito de literatura: (1) como instituição nacional e patrimônio cultural; (2) como sistema de obras, autores e público; (3) como disciplina escolar que se confunde com a história literária; (4) cada texto consagrado pela crítica como sendo literário; e (5) qualquer texto, mesmo não consagrado, com intenção literária, visível num trabalho da linguagem e da imaginação, ou, simplesmente, esse trabalho enquanto tal. Argumenta Chiappini que, tradicionalmente, a escola utiliza a literatura nas acepções 1 , 3 e 4. Embora sem desprezar as outras acepções, especialmente a 2 , afirma que o mais importante seria "exercitar a leitura e a escrita [de textos], para que a reflexão teórica e histórica sobre eles se dê a partir de uma vivência e do processo que os gera: o trabalho criativo com a linguagem, a prática da expressão livre" (2006, p. 22).

Os anos 1980 foram uma época marcada pela redemocratização do país e, por extensão, pela elaboração de inúmeras propostas curriculares de estados e municípios, as quais contaram, em maior ou menor grau, com a ampla participação 
dos professores. Há, inclusive, estudos importantes sobre as mudanças conceituais trazidas por esses documentos. Entretanto, o que esses estudos mostram é que as transformações foram mais evidentes no tratamento da língua propriamente dita do que na literatura (cf. LOUZADA, 1997; OSAKABE, 1987).

$\mathrm{Na}$ última década do século $\mathrm{XX}$, as perspectivas epistemológicas de tratamento da linguagem ampliam-se e diversificam-se. Exemplo disso são os estudos no campo da análise do discurso, da pragmática, da teoria literária (incluindo a estética da recepção), do funcionalismo, da análise da conversação, da linguística textual, entre outros.

Nessa mesma década, são lançados os Parâmetros Curriculares Nacionais (PCNs) de Língua Portuguesa, em volumes diferentes para o $1^{\circ}$ e $2^{\circ}$ ciclos, para o $3^{\circ}$ e $4^{\circ}$ ciclos e para o ensino médio (BRASIL, 1997, 1998, 1999). Ressalte-se que os PCNs surgiram numa conjuntura político-econômica neoliberal, atrelados a políticas de avaliação institucional balizadas pelas instituições de financiamento da educação pública nos países subdesenvolvidos. Ao contrário do que ocorrera nos anos 1980, a participação dos professores na formulação dos parâmetros foi praticamente nula, e, talvez em virtude desse fato, a adesão a eles foi muito baixa.

Os PCNs trazem como proposta básica para o ensino de português o conceito de gêneros textuais, agrupados, de acordo com os estudiosos da chamada
Escola de Genebra, em cinco grandes conjuntos: argumentativos, injuntivos, expositivos, descritivos e narrativos. Sugere o documento que a escola trabalhe textos dos cinco agrupamentos em todos os níveis da escolaridade, mediante os procedimentos de análise e produção, relevando-se a situação comunicativa em que figuram. Há, também, estudos a respeito de conceitos-chave desse documento, alguns deles apontando para os limites da tipologia dos gêneros, como também do tratamento conferido ao texto literário (cf. SUASSUNA, 1998, 1999; VILAR, 2004).

Já neste século, no estado de Pernambuco, como extensão da política de avaliação educacional implantada anteriormente, foi lançada a Base Curricular Comum (BCC) para as redes públicas de ensino. A instituição desse documento deriva de questões postas na operacionalização do Sistema de Avaliação Educacional do Estado de Pernambuco (Saepe), na medida em que os agentes envolvidos na avaliação questionavam, entre outros aspectos, a legitimidade dos instrumentos de avaliação empregados, pautados em currículos previamente traçados e que nem sempre coincidiam com o que, de fato, era ensinado em cada escola. A ideia da base nasce justamente daí: o estado como um todo e os municípios participantes do Saepe negociariam um currículo comum que pudesse orientar a avaliação, dando-se margem para a inserção de uma parte diversificada, própria de cada rede/escola, no sentido 
de respeitar a diversidade inerente a qualquer grupo social e aos processos educativos.

A construção da BCC iniciou-se com sua proposição feita por professores universitários especialistas da área; em seguida, o documento passou por alguns pareceres críticos, também elaborados por especialistas. Essa primeira versão, acrescida da contribuição dos pareceristas, foi discutida em diversas audiências públicas realizadas em todo o estado, até ser publicada em 2008. Posteriormente, houve uma demanda dos próprios professores para que o documento fosse desdobrado com sugestões de atividades e procedimentos que pudessem se adequar às competências traçadas na BCC. São lançadas a público, então, as Orientações Teórico-Metodológicas (OTMs), tanto para o ensino fundamental quanto para o ensino médio.

Partindo desse contexto, quando investigadas as referências que os professores de português/literatura brasileira da rede de ensino estadual de Pernambuco adotam para a definição dos projetos curriculares das escolas em que atuam (SANTOS; SUASSUNA, 2011), chamou-nos atenção a quase ausência da literatura como um componente curricular nas escolhas dos professores. A essa lacuna, somou-se a indefinição no que se refere à concepção de literatura, aos objetivos do ensino desse tipo de texto e ao tratamento metodológico dado a esse conteúdo.

\section{Redimensionando e ressignificando o ensino de literatura}

Os debates recentes sobre o ensino de literatura situam-se num contexto que contempla desde os questionamentos sobre a natureza e as especificidades do texto literário, passando pelo papel da literatura na formação humana, até os procedimentos metodológicos mais adequados. Temos, como ponto de partida para iniciar o debate sobre o ensino de literatura, o artigo de Soares (1999), que trata da escolarização do texto literário. A autora considera que a escolarização da literatura é inevitável, se a tomamos como algo fundamental na formação dos alunos. Porém, precisamos atentar para as formas dessa escolarização. Se o texto literário está na escola para ser dissecado, usado como pretexto para o estudo gramatical, banalizado, trata-se do que Soares chama de "má escolarização". Ao contrário, se a literatura é incluída na escola para ser trabalhada em sua dimensão estética e cultural, para promover uma leitura de fruição, para um melhor entendimento do mundo e do humano, temos a "boa escolarização".

Nessa perspectiva, surge a questão de como fazer essa escolarização da literatura sem descaracterizá-la, sem torná-la um fim em si mesma, o que acaba por negar seu poder de transformação enquanto instrumento de humanização. De acordo com Cosson (2006), a leitura literária não pode ser feita de forma as- 
sistemática; não deve, por um lado, ser pretexto para se elaborar resumos, para se preencher fichas de interpretação ou para se trabalhar gramática, nem deve, por outro lado, ocorrer em nome de um prazer absoluto de ler. É preciso que o professor trabalhe com a literatura segundo os objetivos estipulados a fim de promover o letramento literário dos alunos. Para tal, o autor afirma que, nas aulas de literatura, deve-se desenvolver mecanismos de interpretação para explorar os sentidos, estimular a sensibilidade de troca, bem como incitar a expressão dos sentimentos dos alunos suscitados na experiência de leitura. Nessa orientação, unem-se prazer e saber por meio da literatura no âmbito escolar.

Lajolo (1997) defende que levar em conta as teorias que incluem, na noção de literariedade, o leitor e a prática da leitura é fundamental para inserir a literatura na escola. Ou seja, é preciso considerar a interação texto-leitor para que ocorra, em sala de aula, o que se denomina de "experiência poética". $\mathrm{Na}$ esteira desse pensamento, é preciso conceber a leitura como um processo de interpelação e subjetivação que demanda respostas do leitor. Assim, para que haja uma formação efetiva de alunos leitores, uma metodologia de leitura eficaz é sugerida por Cosson (2006). Essa leitura se daria em três etapas: antecipação - consiste nas várias operações que se realiza antes de penetrar no texto; decifração - consiste no processo de decodificação das letras e das palavras, processo pra- ticamente automático e imperceptível para um leitor maduro; e interpretação - consiste nas relações de inferência que o leitor mobiliza no momento da leitura, no diálogo que estabelece com o texto, tendo como limite o contexto. Dessa maneira, é essencial que o professor vá da antecipação à interpretação para que o aluno/leitor, mobilizando suas vivências e visões de mundo, atualize os sentidos latentes no texto e construa, assim, novas formas de significar sua vida e novas possibilidades de lidar com a realidade.

É preciso, portanto, atribuir à figura do leitor um papel essencial, até então esquecido no circuito de leitura da escola, e, consequentemente, levar em consideração suas experiências de leitura. O professor deve, pois, estar atento aos fatores que influenciam os interesses literários dos alunos (fatores como idade, escolaridade, gênero e nível socioeconômico, por exemplo). Entretanto, é preciso que novos interesses sejam suscitados, para aguçar-lhes o senso crítico. Bordini e Aguiar (1993), com base no método que chamam de "recepcional", sugerem cinco fases sequenciadas que $o$ professor precisa efetuar, visando à promoção da expansão de leitura dos alunos. São elas: determinação do horizonte de expectativas, fase em que o professor diagnostica os interesses dos alunos, a fim de prever rupturas e suas possíveis transformações; atendimento do horizonte de expectativas, etapa em que o professor proporciona à classe leitura de textos que satisfaçam suas necessidades; 
ruptura do horizonte de expectativas, momento em que o professor introduz textos que abalem as certezas literárias e culturais dos alunos; questionamento do horizonte de expectativas, quando o professor compara as duas fases anteriores, fazendo que os alunos analisem dificuldades, desafios e preferências; e ampliação do horizonte de expectativas, passo em que o professor sistematiza, junto com os alunos, os resultados da reflexão feita na fase anterior, assim como as alterações e as aquisições promovidas durante todo esse processo. Podemos perceber, então, que se trata de uma metodologia bastante eficaz para se proporcionar o alargamento das práticas de leitura dos alunos, partindo de seus horizontes de expectativas. Enfim, se forem respeitadas as especificidades do fenômeno literário por meio de uma "boa escolarização", se forem alargadas as concepções de linguagem, de literatura e de leitura por parte dos docentes e se forem ampliados os horizontes de expectativas dos alunos, partindo-se de seus interesses de leitura, então, poderemos promover o letramento literário na escola, formando leitores críticos e criativos capazes de transformação pessoal e social.

Isso posto, cabe perguntar: dentro desse contexto de mudanças e novas proposições para o ensino de português e literatura, como os professores organizam sua prática pedagógica frente às teorias atuais no que concerne ao ensino de português/literatura? As competências indicadas nesses estudos são trabalhadas por esses docentes? As orientações metodológicas sugeridas são seguidas? Há relações entre os documentos curriculares, a prática pedagógica e os livros didáticos adotados? A literatura é um componente curricular autônomo, ou é tratada de modo articulado com a leitura, a produção de textos e a reflexão metalinguística? A partir desses questionamentos, decidimos, então, desenvolver a pesquisa aqui descrita, que tem seus objetivos elencados a seguir.

\section{Procedimentos metodológicos}

A pesquisa, predominantemente qualitativa, interpretativa e etnográfica, foi realizada em duas escolas caracterizadas por perfis diferentes: uma pública estadual de Pernambuco (em que foram observadas aulas numa turma de $2^{\text {o }}$ ano de ensino médio) e uma pública municipal da cidade do Recife (em que foram observadas aulas do $7^{\circ}$ ano do ensino fundamental). A opção por duas escolas de perfis e realidades diferentes justifica-se pelo intuito de se realizar uma análise comparativa entre ambas.

Em cada uma das unidades educacionais, foram colhidos dados com auxílio de protocolos de observação, técnica de coleta de dados que tem a vantagem de captar os fenômenos a serem estudados no ambiente natural em que acontecem. Os materiais de pesquisa envolvidos na coleta dos dados foram diários de campo e um gravador de voz do tipo MP3, 
empregados para o registro das aulas observadas, além de materiais didáticos e instrumentos de avaliação utilizados pelos professores.

Quanto aos critérios de análise, debruçamo-nos sobre: (a) os conteúdos e as competências privilegiados pelos professores; (b) os procedimentos metodológicos adotados para o tratamento do texto literário, considerando as suas especificidades; (c) a possível relação entre as propostas curriculares, a prática docente e o livro didático adotado; (d) a conexão entre a literatura e as demais unidades de ensino de português (leitura, produção textual e reflexão metalinguística).

Cumpre esclarecer que, para empreender a investigação, providenciamos as devidas autorizações para a coleta e o tratamento dos dados, mediante os instrumentos adequados, inclusive o Termo de Consentimento Livre e Esclarecido, assinado pelos gestores das unidades escolares e pelos professores observados. A eles foi assegurado o anonimato quando da divulgação dos dados em textos e eventos de caráter científico.

Para realizarmos a discussão dos resultados de nossa pesquisa, destacamos três situações didáticas que ilustram bem as práticas dos professores observados no que se refere ao ensino de literatura. As duas primeiras situações descritas dizem respeito à prática do professor da escola municipal (denominado de "professor 1") e as duas últimas, às aulas do professor da escola estadual (chamado de "professor 2").
Aula de leitura e interpretação

\section{(?) do poema "Canção do Exílio", de Gonçalves Dias}

O caso em análise revela-nos uma aula em que a interpretação do poema, quando houve, ficou subjugada ao crivo do professor. Assim, apesar de o professor 1 utilizar-se de diferentes métodos para fazer os alunos entenderem o poema, não lhes foi dada voz de expressão no que se refere às suas impressões sobre o texto lido.

O professor 1 inicia a aula pedindo a um grupo de alunos que cada um leia uma estrofe do poema - que consta no livro didático Língua Portuguesa - Projeto $E c o, 7^{\circ}$ ano, de Cristina Azeredo. Após a leitura, o docente distribui vários dicionários para que os alunos busquem o significado das palavras que não conhecem (exílio, gorjeiam, várzeas, cismar, primores etc.). Assim, ele os orienta quanto à questão da ordem alfabética, explicando que as palavras são sequenciadas nos dicionários, e tira dúvidas quando alguns ainda não conseguem apreender os significados de termos que constam na definição, para com eles interpretar as palavras do poema.

Em seguida, o docente pergunta aos alunos o que significa exílio, exilar-se, ao que os alunos respondem lendo as definições do dicionário. Então, ele explica que esse poema é assim intitulado porque seu autor, Gonçalves Dias, estava afastado do Brasil, sua terra natal. Diz, também, que esse é um dos poemas mais 
conhecidos e admirados no país, tendo, inclusive, um de seus trechos incluído no hino nacional. Após isso, ele lê o poema, exaltando a nação brasileira e enaltecendo sua natureza; salienta a semelhança de uma estrofe com o hino nacional, explicando que "o poema veio primeiro", ou seja, exerceu influência na composição do hino. Por fim, fala do desejo de retorno sentido pelo eu lírico/poeta.

No que se refere à proposta de Cosson (2006) para uma metodologia de leitura, vemos, nesse caso, que o professor 1 , apesar de prescindir da antecipação, estabelece com eficácia a fase de leitura da decodificação no momento em que impele os alunos a se esforçarem para buscar os significados das palavras que não conhecem. Essa atividade é essencial para desenvolver a familiaridade dos alunos com termos menos comuns na fala cotidiana, sobretudo porque se trata de uma turma de $7^{\circ}$ ano do ensino fundamental, fase em que se deve construir um vasto domínio semântico de palavras de diversas esferas. Entretanto, a etapa da interpretação ficou realmente comprometida.

Após a decifração do poema, o professor 1, empregando o método expositivo, impõe aos alunos suas interpretações - ou, melhor, a interpretação oficial e autorizada - a respeito do poema. Dessa forma, mesmo que se tenha trabalhado (superficialmente, é válido salientar) noções como as de autoria, intencionalidade e intertextualidade, a leitura acaba tornando-se uma mera obrigação escolar, não tendo eco algum na vida dos educandos (SANTOS, 2009). Quando se trata de literatura, não é só o conteúdo do texto que faz parte do processo de ensino-aprendizagem; é sua condição mesma de texto, abrangendo tanto as questões de produção desse texto quanto de recepção/ percepção por parte dos alunos. "Importa, pois, no âmbito da disciplina Língua Portuguesa, colocar em causa a função de 'literário', e distinguir, na análise, o que diz respeito ao efeito estético e o que diz respeito a outras funções que o texto assume enquanto obra de linguagem" (MAGNANI, 2001, p. 51).

Além disso, esse tipo de abordagem contribui bastante para uma "entronização" do texto literário, na medida em que é legítimo apenas o discurso do professor (balizado pela crítica) a respeito da literatura. Quando não se abre espaço para os alunos expressarem-se diante da leitura de um texto literário, ou quando essa expressão não é considerada, cria-se uma representação de intangibilidade em torno da literatura que provoca um distanciamento entre a obra literária e o educando e que, consequentemente, faz perpetuar o mito de que literatura é um conteúdo escolar "muito difícil".

Nesse sentido, seria mais produtivo que o professor, concluída a fase de decodificação, conversasse mais livremente com os discentes sobre o que foi lido, atentando para a musicalidade do poema e para a inventividade do poeta e extraindo dos alunos suas impressões acerca do texto e os sentimentos por 
este suscitados (considerando-se o fato de que, na vida, mesmo quando crianças, mudamos de escola, de bairro ou de cidade, ou nos afastamos de pessoas de quem gostamos - um “exílio" inevitável).

\section{Leitura da crônica "Floresta} incendiada", de Cecília

\section{Meireles: um exemplo da má}

\section{escolarização da literatura}

Dando continuidade às atividades do livro didático, foi lida a crônica "Floresta incendiada”, de Cecília Meireles, que trata da indignação da poetisa frente às queimadas ocorridas constantemente no morro de Dona Marta. Nessa crônica, a escritora descreve poeticamente os incêndios que presencia e os toma como símbolo para questionar a "humanidade" do ser humano.

Após a leitura dessa crônica, o professor passa a tecer comentários, alegando que queimadas e derrubadas não são algo tão incomum, e pergunta aos alunos se eles já viram uma árvore sendo derrubada, ao que os alunos respondem positivamente. Então, relata um caso em que sua vizinha mandou derrubar um pé de jambo por causa do barulho dos passarinhos e critica-a, bem como critica a derrubada de árvores para se fazer construções. Depois, pergunta aos alunos se eles concordam com a visão pessimista da autora de que "os homens estão ficando piores" no que se refere ao meio ambiente. Os alunos respondem que sim, e o professor, então, faz uma reflexão quanto à limpeza da sala de aula, afirmando que "o aluno que suja a sala é o mesmo que joga lixo na rua e no canal", e busca conscientizá-los de que jogar lixo nas ruas, principalmente na cidade do Recife, causa entupimento de bueiros e, consequentemente, alagamentos.

Logo, podemos perceber que o professor revela uma preocupação de compromisso com a comunidade, ao vincular o tema do texto à realidade dos alunos e ao expandir a reflexão para fora dos limites da escola. Esse intercâmbio entre escola e sociedade é essencial para que os educandos conscientizem-se do seu papel de cidadãos e de agentes na transformação da realidade, no caso, referente ao meio ambiente e à limpeza tanto da cidade quanto do espaço escolar. Entretanto, quando se trata de literatura, estacionar na discussão temática acaba por desconsiderar o texto como trabalho de linguagem e imaginação. Ou seja, o esquecimento da dimensão poética acaba por reduzir o aproveitamento da crônica em sua mensagem.

O objetivo é sugerir que as atividades de leitura propostas ao aluno, quando este se debruça sobre um texto literário, têm sempre de ser centradas no significado mais amplo do texto, significado que não se confunde com o que o texto diz, mas reside no modo como o texto diz o que diz (LAJOLO, 1997, p. 50).

Em seguida, o professor 1 passou uma atividade no quadro, a qual será reproduzida a seguir: 
Atividade de análise do texto "Floresta incendiada" - Cecília Meireles.

1 - A característica principal do texto "Floresta incendiada" é a indignação da autora perante a devastação das florestas brasileiras. A quem ela dirige uma crítica no $4^{\circ}$ parágrafo sobre a responsabilidade de ensinar as novas gerações?

2 - No $5^{\circ}$ parágrafo a autora faz uma comparação entre passado e presente. Copie o trecho que expressa bem essa comparação.

3 - A partir de sua visão pessimista, o que a autora afirma com relação aos seres humanos e seu comportamento perante a natureza?

Ao analisarmos o livro didático da turma, pudemos observar que essas questões propostas pelo docente resultam de uma adaptação simplificada e superficial das questões originais que se seguem ao texto no manual. Em alguns exercícios do livro, ainda podemos notar um caráter reflexivo, na medida em que certas perguntas fazem o aluno atentar para algumas ironias presentes no texto, pedem a sua opinião sobre o estado pessimista da autora, perguntam sobre o fato de os incêndios serem "simbólicos" e ainda os levam a refletir sobre a natureza subjetiva da crônica. Já nas perguntas adaptadas pelo professor 1 , predomina um caráter de identificação de informações no texto e de reprodução de alguns de seus trechos. O docente, ao fim da aula, responde às questões, explicando que "as professorinhas" - resposta da primeira questão - representam "a escola, a educação"; explica, também, a definição de "comparação" - referente à segunda questão -, solicitando que os alunos atentem para a contraposição entre os verbos no passado e no presente; por fim, esclarece o significado da palavra "pessimista" - presente na terceira questão -, usando um aluno como exemplo.

Portanto, novamente, percebemos que foram desprezados a busca de diferentes significados num texto notadamente polissêmico, o trabalho com a linguagem poética (presente, sobretudo, na passagem em que Cecília Meireles personifica o fogo dos incêndios e descreve a agonia das árvores que queimam) e o papel do leitor enquanto elemento fundamental no processo da experiência literária. Dessa maneira, "os exercícios acabam funcionando como uma espécie de filtro seletor em que o relacionamento do leitor com o texto fica distorcido e apequenado, não obstante a virtualidade estética de que 0 texto seja dotado" (LAJOLO, 1997, p. 51).

$\mathrm{Na}$ aula seguinte, o professor 1 passa para os alunos os exercícios do livro didático da seção "A linguagem do texto", ainda referentes à crônica de Meireles. O enfoque desses exercícios é o trabalho com a metalinguagem do texto, especificamente no que se refere à concordância e à retomada de elementos como recursos coesivos. Ocorre que esses exercícios em momento algum se voltam para a significação global do texto, muito menos para sua literariedade. As questões colocam em foco passagens isoladas da crônica que melhor exemplificam o conteúdo linguístico trabalhado, como podemos ver, explicitamente, na segunda questão da seção, transcrita abaixo: 
2 - Releia este trecho da crônica: "Em redor deste vale, tudo era virente e feliz".

a) De acordo com a leitura que você fez do texto, o que "era virente e feliz"?

b) Qual é a função da palavra "tudo" nessa frase?

c) Por que o verbo ser usado nessa frase na terceira pessoa ("era") está no singular?

Assim, ao se trabalhar os pronomes indefinidos funcionando como apostos recapitulativos no processo da anáfora, o texto passa a ser pretexto para se abordar aspectos gramaticais e textuais. Mais uma vez, o questionário valoriza um esforço de compreensão racional, nunca articulado ao lúdico/estético presente na crônica. É preciso, portanto, que as orientações de leitura levem em conta a dimensão estética do texto - não meramente a técnica.

Em síntese, podemos notar que, no que se refere ao ensino reservado ao texto literário, os conteúdos e as competências privilegiados pelo professor 1 dizem respeito à decodificação desse texto, a discussões de caráter temático e ao trabalho com questões gramaticais/textuais. Nesse sentido, podemos afirmar que há uma integração entre o ensino de literatura e o ensino de língua materna (leitura e análise linguística). No entanto, essa integração acaba sendo nociva ao texto literário, por torná-lo repositório de exemplos para se trabalhar questões de análise gramatical e mote para debates estritamente temáticos após sua leitura. De acordo com Perrone, "Estudar literatura apenas a partir da temática é a maneira mais pobre de a conceber. Reduzindo o texto literário à mesmice dos assuntos, a leitura temática empobrece não apenas o texto, mas também o seu leitor" (apud CHIAPPINI, 2005 , p. 256). Isso porque procedimentos desse tipo "pouco ou nada contribuem para a formação de leitores capazes de reconhecer as sutilezas, as particularidades, o sentido, a extensão e profundidade das construções literárias" (PINHEIRO, 2001, p. 70).

Outro problema observado na prática do professor 1 diz respeito à seleção dos textos para se trabalhar em sala de aula e, numa visão mais ampla, ao projeto curricular que a sua prática revela. Apesar dos recentes debates sobre ensino de literatura, que dão destaque especial ao interesse de leitura dos alunos, foi notado que a seleção dos textos e do tema em questão decorreu do livro didático. A temática da natureza foi trabalhada pelo professor, não por conta de uma decisão tomada em conjunto com os alunos, mas porque era o tema trabalhado na primeira unidade do livro didático, intitulado A natureza em prosa e verso. No caso do poema "Canção do exílio", observamos um sério descompasso entre o seu teor nacionalista/ufanista e os horizontes de expectativas dos alunos - crianças de, em média, 12 anos de idade.

Dessa forma, podemos inferir que o projeto curricular que norteia a prática desse professor é subjugado ao conteúdo do manual didático. Apesar de percebermos certas tendências voltadas ao 
letramento durante a observação de suas aulas - provavelmente decorrentes das orientações da BCC -, é notório que os conteúdos, as temáticas e os textos selecionados para o ensino de língua portuguesa são determinados mais pelo manual didático, que funciona como a fonte efetiva do currículo. No que concerne, especificamente, ao ensino de literatura, essa postura traz sérios prejuízos para a promoção do letramento literário dos alunos, pois seus interesses são descartados em nome do que é ditado pelos livros didáticos, que, segundo Freinet, "raramente [...] são feitos para a criança. Eles alegam facilitar, ordenar o trabalho do professor; eles se gabam de seguir passo a passo os programas. Mas a criança acompanhará, se puder... Não é dela que eles se ocupam" (apud CHIAPPINI, 2005, p. 96).

\section{Uma aula de história da literatura sem leitura literária}

A situação que passamos a descrever refere-se à prática do professor 2 , regente de uma turma de $2^{\circ}$ ano do ensino médio. Nessa escola, o ensino de língua materna é dividido em três disciplinas: literatura, português e redação. Para cada turma, havia dois professores: um se encarregava de literatura, e outro, de português e redação. Para essas duas últimas disciplinas, mesmo sendo ministradas pelo mesmo professor, eram reservados horários diferentes em que eram trabalhados conteúdos diversos.
Assim, ao passo que o professor de literatura ensinava o Romantismo, o outro professor, nas aulas de português, trabalhava as regras referentes às flexões dos substantivos - pelo método indutivo, ou seja, mediante a memorização das prescrições e posterior identificação em exercícios do livro didático - e, nas aulas de redação, o gênero informativo - numa perspectiva da tipologia textual clássica "narração-descrição-argumentação". A coordenadora pedagógica, no momento em que solicitamos autorização para realizar a pesquisa na escola, justificou-se dizendo que, apesar de saber que "não é isso que se prega na universidade", era necessário fazer essa separação; do contrário, se fosse um professor só e as três disciplinas fossem integradas, corria-se o risco de o docente dar ênfase à área de sua preferência, minimizando as demais. Afora isso, alegou que a separação facilitava a organização dos horários por parte da gestão. Logo, podemos notar que o currículo referente ao ensino de língua materna comporta um caráter burocrático, na medida em que é formatado com base na organização e categorização dos conhecimentos em detrimento da aprendizagem dos alunos. Ademais, essa justificativa comprova o que Chiappini (2006) afirma quando diz que a divisão entre língua e literatura se dá muito mais por concepções estreitas de língua e de literatura do que por uma didática que favoreça seu ensino.

Para iniciar os estudos sobre o Romantismo brasileiro, esse docente pede 
que a turma se divida em seis grupos de, em média, quatro alunos. Assim, ele enumera os grupos e diz que cada equipe corresponderá a um dos seis tópicos que estão escritos no quadro, a saber:

1 - Uma corte em fuga - os nobres invadem o Rio

2 - Romantismo no Brasil: discurso da nacionalidade

3 - Resgate do mito do território sagrado Von Martius e a gênese do povo brasileiro

4 - Proclamação da independência: impacto na produção cultural

5 - O manifesto romântico brasileiro

6 - A poesia indigenista da $1^{\underline{a}}$ geração - o projeto literário da poesia da primeira geração

Esses temas/títulos foram extraídos de seções do livro didático da turma (Português: texto, interlocução e sentido, de Abaurre et al., Editora Moderna) referentes ao capítulo sobre o Romantismo brasileiro. Dessa forma, o professor 2 solicitou que, depois de realizar a leitura do texto do manual correspondente a seu tópico, cada grupo fizesse um resumo e apresentasse o que havia entendido para o restante da turma; após cada apresentação, ele faria perguntas aos alunos.

No momento das apresentações, os alunos falavam textos memorizados previamente ou reproduziam o texto do livro didático, chegando mesmo a lê-lo. Quando o professor fazia perguntas à equipe, os membros calavam-se; quando as lançava para a turma, os alunos alegavam: "Essa não é minha parte!". Então, ele prosseguia, explicando cada tópico apresentado por meio de uma paráfrase do texto do livro e dando in- formações adicionais sobre o episódio histórico em questão. Na aula seguinte, o professor, a partir do manual didático, escreveu no quadro características, autores e obras referentes à primeira geração da poesia romântica brasileira, conforme o esquema a seguir:

\author{
ROMANTISMONO \\ BRASIL - POESIA \\ $1^{\text {a geração }}$ \\ (indianista/nacionalista/religiosa) \\ - Gonçalves Dias $\rightarrow$ (I-Juca Pirama; Se se morre de amor) \\ - Gonçalves de Magalhães $\rightarrow$ (Suspiros poéticos e saudades)
}

Em seguida, o docente explicou aos alunos as características elencadas, sem, no entanto, buscar as causas dessas características, e salientou que, dos dois autores, Gonçalves Dias é o mais representativo, porém não esclareceu o critério utilizado para essa classificação. Essa falta de porquês revela-nos um modelo de ensino diretivo, baseado na memorização de informações, e não na reflexão e no exercício da crítica e da investigação. Quanto a ter dito que Gonçalves Dias é mais representativo, provavelmente o docente o fez porque é o que consta no livro didático. Isso nos conduz a pressupor que o professor 2 nunca questionou o fato de que o critério para tal afirmação, longe de ser a qualidade dos textos de Gonçalves Dias, é, na verdade, a adequação da sua obra às características convencionadas para aquela geração. Dessa forma, podemos notar que o professor desconsidera que 
os estilos e as características dos movimentos literários são abstrações construídas a posteriori pelos críticos, uma vez que são as obras que determinam essas sistematizações. Ademais, dificilmente uma obra identifica-se inteiramente com essas posteriores esquematizações, pois se trata de generalizações (COSSON, 2006).

$\mathrm{Na}$ atividade de apresentação, observamos a reprodução literal do texto do livro didático (lido ou decorado) por parte dos discentes, cujo discurso não era de autoria própria, uma vez que o conteúdo da aula não resultou de um conhecimento construído pela turma, juntamente com o professor, por meio de uma reflexão sistemática. Essa reprodução também ocorreu por parte do docente, tendo em vista que se limitou a parafrasear o texto do manual didático e a extrair dele o conteúdo para suas aulas, acrescentando algumas poucas informações - o que revela um ensino superficial de caráter informacional. A esse fato, podemos associar a seguinte afirmação de Chiappini:

[...] o fato de tratar-se de um manual - o saber ao alcance da mão - faz do professor um repetidor que não se interroga sobre aquilo que transmite, e do aluno, um executante que não se interroga sobre aquilo que executa. [...]. Um livro para fazer isso, para colocar o saber ao alcance da mão, tem que comprimir, diluir, homogeneizar, congelar, desistoricizar o saber. Ele tem de dar a impressão de que o saber é neutro, de que é o mesmo para todos os pontos de vista e para todos os que o buscam, de que o saber é apenas resultado, pronto e acabado, e não uma construção (2005, p. 96-112).
As observações realizadas permitiram-nos notar que o professor 2 adota integralmente o livro didático como base curricular para sua prática pedagógica. Assim, se pensarmos em termos de formação de leitores literários, compromete-se tanto a metodologia - como vimos acima - quanto o conteúdo das aulas de literatura. Com efeito, resta claro, ao analisarmos esse manual, que sua proposta de trabalho está calcada na história da literatura em detrimento da compreensão, da interpretação e da fruição das obras literárias. Ensinar literatura por meio da apreensão de técnicas e períodos literários não vai resultar em alargamento dos limites culturais dos alunos. Assim, uma prática pedagógica significativa é aquela que proporciona ao discente a vivência da experiência literária. Por isso, concordamos com Bordini e Aguiar, quando dizem que,

[...] antes de formalizar o estudo do texto por essas vias, é preciso vivenciar muitas obras para que estas venham a preencher os esquemas conceituais. [...]. Será no $2^{\circ}$ grau que a sistematização teórica do conhecimento literário poderá ser introduzida, desde que, mesmo então, seja fundada na leitura prévia de textos (1993, p. 17).

Logo, é pouco proveitoso ensinar os educandos a memorizarem as características de um estilo de época - situando a produção da literatura em blocos estanques de períodos literários - se eles não têm uma compreensão mais ampla e crítica do objeto literário: o texto.

Ainda assim, dentro dessa proposta de estudo da história da literatura, há 
uma tendência, como restou-nos comprovado nessa situação didática, de se encarar o processo histórico como a visão estreita de uma mera sucessão de eventos. Essa visão trata os fatos relacionados à literatura por um viés enciclopédico, compartimentando-os em períodos isolados e em individuações descontínuas do processo cultural. Conforme Chiappini, essa abordagem contribui sobremaneira para "homogeneizar e simplificar o saber, diluindo as contradições e as particularidades, numa ilusória visão harmônica do mundo e, sobretudo, agravando a ruptura já existente entre a escola e a vida" (2005, p. 97).

Além disso, apesar de o conteúdo da aula privilegiar a história da literatura, as características do movimento romântico não foram historicizadas. Ou seja, o professor 2 não estabeleceu vínculos entre os episódios históricos apresentados e os ideais do Romantismo, desconsiderando a relação dialógica que há entre esse dois elementos - ainda mais quando se trata de um estilo de época tão marcadamente definido por questões históricas (como é visto, por exemplo, na associação entre a independência do Brasil e a necessidade de criar, pela via da literatura, uma identidade nacional baseada na valorização da figura do índio, uma vez que esse era o habitante do Brasil antes de os portugueses chegarem aqui; na correspondência entre a instauração da burguesia enquanto produtora de literatura e o surgimento dos gêneros romance, novela e conto; e na relação entre a expansão do público leitor feminino e o advento de narrativas de perfis femininos que defendiam valores a serem seguidos pelas mulheres). Todavia, como já anunciamos, essas ligações não foram feitas, na medida em que fatos da história e características a respeito dessa escola literária foram abordados de forma isolada, em tópicos separados.

É importante salientar, como bem afirmam Bordini e Aguiar (1993), que não se trata de negar a história da literatura enquanto um conhecimento válido no processo de letramento literário escolar (sobretudo no ensino médio); mas, antes, de valorizá-la por meio de uma contextualização que parta da leitura efetiva das obras, num processo reflexivo de construção de conhecimentos, e de reconhecer sua importância com base em uma metodologia que contemple o diálogo que a obra estabelece com os fatos históricos do período.

\section{Atividade sobre o poema "Olhos verdes", de Gonçalves Dias: um exercício da obrigação escolar}

Na aula seguinte, o professor 2 passou para os alunos o exercício do livro didático referente ao poema "Olhos verdes", de Gonçalves Dias. Ele leu o fragmento do texto que constava no livro e as perguntas (explicitadas abaixo); depois, deixou que os alunos respondessem. 
6 - O eu lírico se apaixona por uma mulher depois de ver seus olhos verdes. Que efeitos esse fato tem sobre ele? Explique.

7 - A referência à beleza da amada é feita com base na cor de seus olhos. Que recurso o poeta utiliza para caracterizá-los?

a) Que elementos do poema indicam que o sofrimento do eu lírico já estava anunciado nos olhos da amada? Explique por quê.

b) Quem afirma no poema: "Eram verdes sem esp'rança" e por quê?

8 - Em todas as estrofes do poema há um mesmo refrão, com pequenas alterações. Transcreva-os no caderno.

a) A que tipo de poesia a presença do refrão nos remete?

b) O uso do refrão permite identificar certa influência literária na lírica de Gonçalves Dias que a distingue das outras obras desse autor. Que influência seria essa? Por que ela revela uma diferença em relação à produção indianista do autor?

Porque vários alunos estavam fazendo barulho durante a aula, o professor ameaçou-os, dizendo, com um tom de autoridade, que perto do fim da aula iria passar "de caderno em caderno, dando o visto" para saber quem estava fazendo e quem estava conversando. Para aqueles que tivessem feito a atividade, ele disse que "daria ponto". Assim, os alunos passaram a fazer silêncio e muitos copiaram a atividade de outros colegas sem que o professor visse; quando ele se aproximava, fingiam que estavam fazendo os exercícios. Depois, o professor passou de classe em classe, averiguando se o exercício estava feito e conferindo se a letra no caderno de alguns alunos eram mesmo suas, e, por fim, deu as respostas das questões sem discuti-las.
Dessa forma, fica claro que a leitura do texto literário e a exploração de seus recursos expressivos por meio das questões do exercício foram totalmente secundarizadas, uma vez que esse trabalho revestiu-se da artificialidade típica do ensino tradicional. A leitura, portanto, não interpelou os alunos, e a tarefa ganhou um tom de execução e de obrigação, na medida em que o professor utilizou o exercício como um instrumento para promover a disciplina da turma, subjugando-o à atribuição de nota. Haja vista que não se identificaram com o texto (e que não houve qualquer esforço da parte do professor para tal), os alunos não empregaram energia para entendê-lo, sequer para significá-lo com base em suas experiências. Como seu papel na recepção textual é desprezado, os educandos não se veem como coenunciadores do texto; assim, a literatura, para eles, torna-se impenetrável e indecifrável (MARTINS, 2009).

No que se refere ao exercício do manual, percebemos que o poema em questão acaba servindo para ilustrar traços do estilo de época, características do autor, além de estar incompleto. Some-se a isso o fato de que os autores omitem sua referência bibliográfica. Essa preferência por excertos descontextualizados e desligados do livro que os comporta

desvirtua o universo de sentidos das obras, produzindo no imaginário do aluno leitor um caos de representações desarticuladas que nem de longe correspondem ou insinuam a proposta de cada original, e acabam por fazer da noção de literatura assim construída uma colcha de retalhos em que nada tem a 
ver com nada. Ou melhor, tudo tem a ver com as intenções (nem sempre louváveis) daquele que seleciona os textos e os recorta (BORDINI; AGUIAR, 1993, p. 37).

A poética do texto, então, é reduzida à identificação de influências de outros períodos literários e de características do movimento, o que restringe sua interpretação à catalogação de itens em detrimento da fruição do poema, da experiência poética. No mais, a ilusão de que há "respostas certas", quando se trata do trabalho com a literatura, contribui para a entronização do texto (ou melhor, do fragmento). Assim como ocorreu com o professor 1, o professor 2 dá as "respostas certas", tidas como as melhores e, portanto, difíceis de serem alcançadas pelos alunos e/ou contestadas por eles. Dessa maneira, promove-se um distanciamento entre literatura e aluno, uma vez que este passa a representar aquela como um repositório de ideias fixas, verdadeiras, indiscutíveis e intangíveis.

O trabalho didático-pedagógico seria mais proveitoso se o professor 2 dedicasse o mesmo tempo da aula a uma discussão do poema, fazendo uma contraposição entre a postura do poeta e a postura dos alunos em relação a um amor não correspondido e voltando seus esforços para uma exploração dos recursos estéticos que revelam o sofrimento do eu lírico, o que certamente configuraria um ensino capaz de despertar o interesse pelo texto literário e propiciar a experiência poética por parte dos educandos. Em contrapartida, como vemos, "solicita-se do aluno uma atitude meramente passiva e reprodutora diante de um texto dado como 'exemplar', ao mesmo tempo em que se trabalha aspectos estáticos da literatura passíveis de serem operacionalizados e comportamentalizados" (MAGNANI, 2001, p. 48).

Em síntese, temos, como objeto de estudo e habilidades privilegiados pelo professor 1 , a apreensão da história da literatura, usualmente na sua forma mais simplificada, ou seja, enquanto uma cronologia literária que leva em conta características de estilos de época, cânone e dados das obras de autores. $\mathrm{O}$ texto literário, quando compareceu, reduziu-se à apresentação de um fragmento como pretexto para se comprovar as características do movimento romântico, o que serviu como exercício do cumprimento das tarefas escolares sem sentido e sem reflexão. Dessa forma, a única razão que resta para os alunos estudarem literatura é a presença desse tipo de conteúdo nos exames vestibulares.

Quanto à metodologia, por eleger um ensino de caráter enciclopédico, o professor 2 priva os alunos da experiência literária, na medida em que os conduz a entrar em contato com poucas obras, conhecendo muito pouco sobre cada um desses textos, sobretudo no que eles têm de singular. Essa abordagem histórica, portanto, não incentiva a leitura, uma vez que o texto literário desempenha uma função secundária e ilustrativa, e prescinde de uma sistematização metodológica que favoreça o letramento literário, já que se espera do aluno apenas a assimilação de informações que pouco lhe servem para a vida concreta, numa 
postura acrítica em relação ao conhecimento trabalhado.

Em consonância com esse ensino de caráter histórico voltado para o vestibular, o professor 2 submete seu projeto curricular ao livro didático, seguindo-o à risca e com exclusividade - tenha sido ele ou não a indicá-lo. Além disso, esse ensino de língua materna fragmentado em literatura - em que se estudam os períodos literários -, português - em que se estudam regras gramaticais - e redação - em que se estudam tipos textuais - revela-nos que há uma desconsideração das tendências presentes nos documentos curriculares oficiais de Pernambuco (BCC e OTM). Embora ainda apresentem indefinições quanto ao objeto de estudo literário e falta de critérios quanto aos procedimentos metodológicos para 0 ensino de literatura, como apontam Silva e Suassuna (2012), esses documentos já revelam avanços na área à medida que defendem a integração do ensino de língua e literatura tanto no ensino fundamental como no ensino médio e a leitura e análise de textos literários.

\section{Quadro 1 - Resumo comparativo}

\begin{tabular}{|c|c|c|}
\hline & $\begin{array}{c}\text { Professor da escola municipal } \\
\text { - ensino fundamental }\end{array}$ & $\begin{array}{l}\text { Professor da escola estadual } \\
\text { - ensino médio }\end{array}$ \\
\hline $\begin{array}{l}\text { Conteúdos e } \\
\text { competências }\end{array}$ & $\begin{array}{l}\text { - leitura como sinônimo de decodificação; } \\
\text { - leitura para interpretação (do professor) no nível } \\
\text { temático; } \\
\text { - texto literário como pretexto para análise gramati- } \\
\text { cal e textual. }\end{array}$ & $\begin{array}{l}\text { - memorização de períodos históricos, de característi- } \\
\text { cas de movimentos literários, de dados sobre autores } \\
\text { representativos e de obras canônicas; } \\
\text { - leitura de fragmento de poema do autor estudado } \\
\text { para identificação de características. }\end{array}$ \\
\hline $\begin{array}{l}\text { Procedimentos } \\
\text { metodológicos }\end{array}$ & $\begin{array}{l}\text { - incitação ao uso do dicionário por parte dos alunos; } \\
\text { - exposição do professor (ora diretiva, ora entremea- } \\
\text { da de questionamentos e reflexões); } \\
\text { - resolução de exercícios do livro didático em con- } \\
\text { junto com a turma. }\end{array}$ & $\begin{array}{l}\text { - apresentação dos alunos sobre tópicos do livro di- } \\
\text { dático para memorização das informações sobre o } \\
\text { estilo de época mediante reprodução do que consta } \\
\text { no manual; } \\
\text { - exposição diretiva do professor; } \\
\text { - resolução de exercícios do livro didático realizada de } \\
\text { forma impositiva e mecânica. }\end{array}$ \\
\hline $\begin{array}{l}\text { Integração } \\
\text { entre literatura } \\
\text { e os demais } \\
\text { eixos do } \\
\text { ensino de } \\
\text { português }\end{array}$ & $\begin{array}{l}\text { - há integração entre o ensino de língua e de literatu- } \\
\text { ra, porém não são respeitadas as especificidades } \\
\text { do texto literário. Este é subjugado ao ensino da } \\
\text { leitura, funcionando como um gênero como outro } \\
\text { qualquer para se trabalhar a temática definida pelo } \\
\text { livro didático, e ao ensino de análise linguística, } \\
\text { servindo como repositório de exemplos para se } \\
\text { trabalhar questões gramático-textuais. }\end{array}$ & $\begin{array}{l}\text { - não há conexão entre ensino de língua e de litera- } \\
\text { tura. O ensino de língua materna, nessa escola, é } \\
\text { dividido em (história da) literatura, português (que se } \\
\text { confunde com gramática normativa) e redação. Essa } \\
\text { separação é justificada pela coordenadora pedagó- } \\
\text { gica por uma necessidade de facilitar a organização } \\
\text { das atividades escolares e de controlar a garantia de } \\
\text { que cada um desses saberes está sendo ensinado - } \\
\text { o que revela tanto um ensino de caráter burocrático, } \\
\text { com foco no planejamento, e não na aprendizagem } \\
\text { do aluno, quanto concepções estreitas de língua e } \\
\text { de literatura. }\end{array}$ \\
\hline $\begin{array}{l}\text { Relação entre } \\
\text { as propostas } \\
\text { curriculares, a } \\
\text { prática docente } \\
\text { e o livro } \\
\text { didático }\end{array}$ & $\begin{array}{l}\text { - o professor } 1 \text { leva em conta orientações da BCC } \\
\text { quanto a práticas de letramento; no entanto subju- } \\
\text { ga suas aulas ao livro didático, sobretudo no que } \\
\text { diz respeito à seleção dos textos e à definição dos } \\
\text { temas trabalhados com os alunos. A literatura, por } \\
\text { sua vez, não é estudada de forma adequada, re- } \\
\text { alidade que resulta de uma possível carência na } \\
\text { formação do professor nessa área e se mantém } \\
\text { devido às lacunas presentes na BCC e nas OTMs } \\
\text { quanto ao tratamento desse tipo de texto. }\end{array}$ & $\begin{array}{l}\text { - o professor } 2 \text { submete seu projeto curricular integral- } \\
\text { mente ao livro didático, reservando à literatura, na } \\
\text { esteira da visão tradicional, um ensino de caráter his- } \\
\text { tórico que relega a leitura das obras. Desse modo, o } \\
\text { docente desconsidera as orientações da BCC e das } \\
\text { OTMs, que, apesar de revelarem indefinições, têm } \\
\text { como foco do ensino de literatura a leitura das obras. }\end{array}$ \\
\hline
\end{tabular}




\section{Considerações finais}

Ao término desta pesquisa, percebemos que, apesar de se tratar de diferentes níveis de ensino, nenhum dos professores investigados promove uma adequada escolarização da literatura, na medida em que não compreendem a literatura à luz de uma perspectiva mais ampla e tomam como base de suas aulas o livro didático, que raramente aborda $o$ fenômeno literário de forma adequada.

Ainda que o professor 1 promova trabalhos de leitura sistemáticos, os conteúdos privilegiados e as metodologias adotadas não favorecem o letramento literário, uma vez que não contemplam a dimensão lúdica e estética dos textos. Assim, há uma integração entre ensino de língua e de literatura, porém o texto literário é subjugado aos exercícios de leitura e de análise linguística, sem que suas especificidades sejam respeitadas.

Já o professor 2 restringe o ensino de literatura a um inventário de períodos literários, de características de movimentos, autores representativos e suas obras canônicas. Não é realizada a leitura dessas obras; apenas nos exercícios propostos pelo manual didático, para reconhecimento de características e identificação de categorias literárias, é que um ou outro fragmento do texto costuma ser lido - o que notadamente prejudica a formação de leitores de literatura.

O papel do leitor como coenunciador que dialoga com o texto e como construtor de sentidos a partir do texto, tanto na prática do professor 1 quanto na prática do professor 2, é totalmente desprezado, pois não se levam em conta nem seus interesses de leitura, nem sua impressões e interpretações acerca do texto estudado. Não há um equilíbrio entre seus interesses de fruição pessoal e as necessidades de escolarização do texto literário em ambas as práticas. Além disso, tal desprezo pela leitura (quando há) do aluno é inverso à valorização da interpretação ilustre e autorizada do professor ou do livro didático. Assim, as informações que estes detêm e transmitem são tratadas como verdades indiscutíveis, e não como ferramentas que ajudem os discentes a conferirem sentido ao texto. Essa situação acaba por torná-los espectadores silenciosos e apáticos do estudo da literatura, revelando trabalhos inadequados e infrutíferos para a formação e o amadurecimento de futuros leitores desse tipo de texto.

Nessa perspectiva, percebemos que a adoção acrítica do livro didático contribui bastante para fomentar o quadro acima descrito, pois, nos manuais dos dois professores observados, à leitura seguiam-se exercícios gramaticais ou interpretações com itens programados e direcionados para uma compreensão literal e primária, sem qualquer relação com o caráter artístico do texto literário. As atividades do livro, então, seguidas à risca, sem discussão ou reflexão do professor com os alunos, acabam por adquirir um caráter de obrigação e execução, em que os discentes são levados a 
crer que a razão do estudo da literatura é o mero cumprimento de tarefas escolares sem sentido para sua vida, senão para que sejam aprovados na escola e/ ou no vestibular. Parece ser da essência mesma do manual a homogeneização dos saberes literários, que nega a experiência poética como algo que deve ser vivenciado, refletido e construído, não algo imposto por meio de interpretações que se recebem prontas. Assim, o uso indiscriminado do livro didático torna $o$ professor um "aplicador", na medida em que este não reflete sobre o que ensina aos seus "alunos-máquinas", os quais têm tolhida sua capacidade de questionar, opinar e expressar-se. Enfim, por comportar "o saber" necessário, o manual didático termina por afastar o aluno dos livros, das bibliotecas, das bibliografias, do diálogo com outros leitores, do diálogo com os autores e do diálogo consigo mesmo.

Essa realidade pode ser consequência da combinação de vários fatores, que vão desde as condições sociais em que a escola está inserida até a falta de formação no que se refere aos estudos recentes sobre uma pedagogia significativa para o ensino da literatura, que a trate como um meio de se (re)conhecer transfigurado nas palavras do autor, de reconhecer o mundo transfigurado no texto. Como pudemos constatar por meio desta investigação, essa falta de formação literária dos professores aponta para um ensino que desabona uma vivência relevante das obras literárias por parte dos alunos, fazendo persistir um modelo de ensino tradicional problemático.

A partir dos indícios de nossa pesquisa, faz-se necessário, portanto, que haja uma maior ênfase quanto a uma didática do texto literário nos cursos de graduação em Letras no estado de Pernambuco. Igualmente, é importante que esse tema ganhe destaque nos programas de formação continuada, a fim de superarmos as barreiras do ensino tradicional e do livro didático, para que os alunos tenham, na escola, através do estudo da literatura, a oportunidade de expandir seus horizontes de leitura; de experienciar o texto literário no que ele tem de lúdico e de humanizador; de descobrir sentidos para ressignificar sua realidade a partir do cuidado, do humor e do amor; de refletir sobre si e sobre o outro; de elaborar seus sentimentos para melhor lidar com as complexidades da vida e das pessoas; e, enfim, de "desver o mundo para encontrar nas palavras novas coisas de ver", segundo versos do poeta Manoel de Barros.

\section{Et comment est l'enseignement} de la littérature brésilienne? Un étude de pratiques aux nivaux "collège" et "lycée"

\section{Resumé}

En considérant le contexte actuel de l'élargissement de la conception de langue et de littérature, nous souhaitons décrire et analyser des pratiques de l'enseignement de la littérature 
brésilienne dans les nivaux "collège" et "lycée" et vérifier si les contenus et les méthodes adoptés favorisent la formation des lecteurs littéraires. Entre autres, nous avons utilisé les travails de Bordini et Aguiar (1993), Chiappini (2006) et Cosson (2006). Em ce qui concerne la méthodologie, nous effectuons une recherche qualitative et ethnographique par l'obsérvation des cours de littérature brésilienne dans deux écoles de profils différents: une publique municipale de Recife ("collège") et une publique de l'État du Pernambouc ("lycée"). Nous avons remarqué, donc, des pratiques qui ne favorisent pás la formations de lecteurs littéraires Tandis que un professeur réduit leurs classes à l'étude de l'histoire littéraire, l'autre ne considère pas les aspects esthétiques de ce genre, et ne tient pas en considération des interprétations des élèves.

Mots-clé: Enseignement de la littérature. Formation de lecteurs. Pratique pédagogique.

\section{Nota}

O livro foi publicado, em suas primeiras edições, pela Associação dos Secretários Municipais de Educação do Oeste do Paraná (Assoeste). A partir de 1997, a edição foi assumida pela Editora Ática, e a obra foi revista e ganhou novo título, passando a intitular-se apenas $O$ texto na sala de aula.

\section{Referências}

BARBOSA, Socorro de Fátima Pacífico. A hora e a vez dos clássicos na escola. Presença Pedagógica, v. 14, p. 35-41, 2008.

BRASIL. SEF/MEC. Parâmetros Curriculares Nacionais: língua portuguesa $-1^{\mathrm{a}}$ a $4^{\mathrm{a}}$ série. Brasília: SEF/MEC, 1997.
. Parâmetros Curriculares

Nacionais: língua portuguesa $-5^{\mathrm{a}}$ a $8^{\mathrm{a}}$ série. Brasília: SEF/MEC, 1998.

BRASIL. SEMTEC/MEC. Parâmetros Curriculares Nacionais do Ensino Médio: parte II - linguagens, códigos e suas tecnologias. Brasília: SEMTEC/MEC, 1999.

BORDINI, Maria da Glória; AGUIAR, Vera Teixeira de. Literatura: a formação do leitor - alternativas metodológicas. 2. ed. Porto Alegre: Mercado Aberto, 1993.

CHIAPPINI, Lígia. Reinvenção da catedral: língua, literatura, comunicação - novas tecnologias e políticas de ensino. São Paulo: Cortez, 2005.

. Gramática e literatura: desencontros e esperanças. In: GERALDI, João Wanderley (Org.). O texto na sala de aula. 4. ed. São Paulo: Ática, 2006. p. 17-25.

COSSON, Rildo. Letramento literário: teoria e prática. São Paulo: Contexto, 2006.

LAJOLO, Marisa. Do mundo da leitura para a leitura do mundo. 3. ed. São Paulo: Ática, 1997.

LIMA, Aldo de. Políticas educacionais e ensino de literatura brasileira. Recife: Editora Universitária da UFPE, 1996.

LOUZADA, Maria Sílvia Olivi. A interação língua e literatura na perspectiva dos currículos. In: GREGOLIN, Maria do Rosário V.; LEONEL, M. C. (Orgs.). O que quer, o que pode esta língua? Brasil/Portugal: o ensino de língua portuguesa e de suas literaturas. FCL-UNESP, Araraquara, 1997. p. 45-53.

MAGNANI, Maria do Rosário Mortatti. Leitura, literatura e escola. São Paulo: Martins Fontes, 2001.

MARTINS, Ivanda. A literatura no ensino médio: quais os desafios do professor? In: BUNZEN, Clécio; MENDONÇA, Márcia (Orgs.). Português no ensino médio e formação do professor. São Paulo: Parábola Editorial, 2009. 
OSAKABE, Haquira. Ensino de gramática e ensino de literatura. Linha d'água, n. 5, p. 57-62, 1987.

PINHEIRO, Hélder. Reflexões sobre o livro didático de literatura. In: BUNZEN, Clécio; MENDONÇA, Márcia (Orgs.). Português no ensino médio e formação do professor. São Paulo: Parábola Editorial, 2009 .

SANTOS, Jailton Jáder Nóbrega; SUASSUNA, Lívia. Currículo de língua portuguesa - como os professores definem o que ensinar? Estudo de uma escola estadual de Pernambuco. Relatório de Pesquisa Pibic. Recife: UFPE, 2011.

SANTOS, Reginaldo Clécio. Ensino de literatura: a hora e a vez do leitor. Leitura - Teoria e Prática, v. 27, p. 24-30, 2009.

SILVA, Marcela Thaís Monteiro; SUASSUNA, Lívia. Ensino de literatura brasileira: representação nos documentos curriculares oficiais atuais do Estado de Pernambuco (BCC e OTM). Relatório de pesquisa Pibic/ Facepe/CNPq, Recife, 2012.

SOARES, Magda. Concepções de linguagem e o ensino da língua portuguesa. In: BASTOS, N. B. (Org.). Língua portuguesa: história, perspectivas, ensino. São Paulo: Educ, 1998.

A escolarização da literatura infantil e juvenil. In: EVANGELISTA, Aracy et al. A escolarização da leitura literária: o jogo do livro infantil e juvenil. Belo Horizonte: Autêntica, 1999.

SUASSUNA, Lívia. O que são, como e por que se escreveram os Parâmetros Curriculares Nacionais de língua portuguesa. In: MARINHO, Marildes; SILVA, Ceres (Orgs.). Leituras do professor. Campinas: Mercado de Letras, 1998. p. 175-184.

. Parâmetros Curriculares Nacionais de língua portuguesa para o terceiro e quarto ciclos: uma apreciação crítica. In: MARCUSCHI, B. (Org.). Formação do educador, avaliação e currículo. Recife: Ed. da UFPE, 1999. p. 79-116.
VILAR, Socorro de Fátima Pacífico. PCNs e literatura: novas roupagens para velhos problemas. In: SOUSA, Maria Ester Vieira de; VILAR, Socorro de Fátima P. (Orgs.). Parâmetros Curriculares em questão: o ensino médio. João Pessoa: Editora Universitária UFPB, 2004. 